\title{
Expressions of heat shock protein 90, inducible nitric oxide synthase, and vascular endothelial growth factor in the skin of diabetic rats
}

\author{
Khaled Z. Alawneh ${ }^{(1 D}$, Liqaa A. Raffee ${ }^{2}$ (D), Musa A. Alshehabat ${ }^{3}$ (i) and Ahed Jumah Alkhatib ${ }^{4}$ (D) \\ 1. Department of Radiology, Faculty of Medicine, Jordan University of Science and Technology, Irbid 22110, Jordan; \\ 2. Department of Accident and Emergency, Faculty of Medicine, Jordan University of Science and Technology, Irbid \\ 22110, Jordan; 3. Department of Veterinary Clinical Sciences, Faculty of Veterinary Medicine, Jordan University of \\ Science and Technology, Irbid 22110, Jordan; 4. Department of Legal Medicine, Faculty of Medicine, Jordan University of \\ Science and Technology, Irbid 22110, Jordan. \\ Corresponding author: Khaled Z. Alawneh, e-mail: kzalawneh0@just.edu.jo \\ Co-authors: LAR: laraffee5@just.edu.jo, MAA: maalshehabat@just.edu.jo, AJA: ajalkhatib@just.edu.jo \\ Received: 23-03-2021, Accepted: 08-06-2021, Published online: 13-07-2021 \\ doi: www.doi.org/10.14202/vetworld.2021.1804-1807 How to cite this article: Alawneh KZ, Raffee LA, Alshehabat MA, \\ Alkhatib AJ (2021) Expressions of heat shock protein 90, inducible nitric oxide synthase, and vascular endothelial growth \\ factor in the skin of diabetic rats, Veterinary World, 14(7): 1804-1807.
}

\begin{abstract}
Background and Aim: Chronic skin ulceration is a common and painful condition that affects about $15 \%$ of patients with diabetes worldwide. The aim of this study was to evaluate the expressions of heat shock protein 90 (HSP 90), inducible nitric oxide synthase (iNOS), and vascular endothelial growth factor (VEGF) in the skin of diabetic rats.

Materials and Methods: A total of 20 rats were divided randomly into two equal groups. Diabetes mellitus (DM) was induced in the rats of Group 2, whereas the rats in Group 1 were kept healthy and served as control. DM was induced by a single intraperitoneal injection of alloxan monohydrate at $120 \mathrm{mg} / \mathrm{kg}$. Rats were considered diabetic if the blood glucose level was above $200 \mathrm{mg} / \mathrm{dL}$. After induction of DM, the rats were monitored daily for 28 days. On day 28, the rats were humanely euthanized, and full-thickness skin punch biopsy was obtained from the dorsal side of the thoracolumbar region. Indirect immunoperoxidase staining was used to evaluate the expressions of HSP 90, iNOS, and VEGF in the skin tissue specimens.
\end{abstract}

Results: The expressions of HSP 90, iNOS, and VEGF in the skin were significantly higher in diabetic rats than in the control rats. On day 28 in diabetic rats, a positive correlation $(\mathrm{r}=0.65, \mathrm{p}=0.01)$ was detected between mean blood glucose level and the expression levels of HSP 90, iNOS, and VEGF.

Conclusion: The results of this study indicated that DM upregulated the expressions of HSP 90, iNOS, and VEGF in the skin tissues of diabetic rats and may impact the healing of skin wounds. However, this study was preliminary and further studies to investigate this relationship are warranted.

Keywords: diabetic foot, endocrine system, vascular injury, wound healing.

\section{Introduction}

Diabetes mellitus (DM) can result in serious complications, including cardiovascular disease, chronic skin ulceration, poor wound healing, cataract, retinopathy, nephropathy, and polyneuropathy [1-6]. Chronic skin ulceration, such as diabetic foot ulcer, is a common and painful condition that affects about $15 \%$ of patients with DM worldwide [7]. Although the exact mechanisms of impaired wound healing and development of diabetic foot in patients with DM are not fully understood, results of recent clinical studies have indicated involvement of local sepsis, epithelial damage, immune system impairment, and local ischemia secondary to poor vascular flow as the potential mechanisms [7-10]. Moreover, advanced

Copyright: Alawneh, et al. Open Access. This article is distributed under the terms of the Creative Commons Attribution 4.0 International License (http://creativecommons.org/licenses/ by/4.0/), which permits unrestricted use, distribution, and reproduction in any medium, provided you give appropriate credit to the original author(s) and the source, provide a link to the Creative Commons license, and indicate if changes were made. The Creative Commons Public Domain Dedication waiver (http:// creativecommons.org/publicdomain/zero/1.0/) applies to the data made available in this article, unless otherwise stated. glycation end products, oxidative stress, and lowgrade inflammation have been reported to mediate hyperglycemia-induced cell dysfunction in patients with DM [7-9].

The important roles of heat shock proteins (HSPs) 47 and 70 in the wound healing process of patients with DM have been proposed previously [7-9]. Increased expression levels and plasma concentrations of HSP 47 and HSP 70 have been found in the wounds of diabetic animals [7-9]. The roles of these HSPs (47 and 70) have been extensively studied, but there is a lack of research on the role of HSP 90 in the wound healing of diabetic animals. Inducible nitric oxide synthase (iNOS) has been found to play a major role in posttranslational modification, which triggers insulin resistance in obesity and aging [10]. NO, which is catalyzed by iNOS and is a potent oxidant, has been found to modulate insulin secretion, angiogenesis, nociception, inflammation, and pain [11-15]. During wound healing in patients with DM, excess levels of NO and other oxygen free radicals, such as peroxynitrite and peroxynitrous acid, result in severe endothelial damage and further matrix 
destruction [15]. Furthermore, the expression of iNOS has been suggested to be upregulated by various insulin resistance inducers, including pro-inflammatory cytokines, such as vascular endothelial growth factor (VEGF) [16]. VEGF is considered an important signal protein that is produced by cells to stimulate angiogenesis, particularly in injured or healing tissues [16]. Locally released VEGF in injured tissues has been found to promote wound healing and reduce the risk of diabetic foot ulcers [15].

The hypothesis in this study was that the expressions of HSP 90, iNOS, and VEGF were enhanced in the dermal tissues of diabetic rats and that the interactions among these molecules may explain some of the complex mechanisms of wound healing in patients with DM. Therefore, the objective of this study was to determine the expression levels of HSP 90, iNOS, and VEGF in the skin of rats with alloxan-induced diabetes.

\section{Materials and Methods}

\section{Ethical approval}

This study was approved by the Ethics Committee of the Jordan University of Science and Technology (ACUC number 16-03-03-36).

\section{Study period and locations}

This study was performed from June to September 2015. All experimental procedures were performed at the Animal House of Jordan University of Science and Technology.

\section{Animals}

Twenty adult albino rats weighing approximately 150-180 g were randomly allocated into the following two groups (10 each): Control group (Group 1) and experimental group (Group 2). All rats were housed individually in cages and offered feed and fresh drinking water ad libitum. The rats were maintained at room temperature $\left(23-24^{\circ} \mathrm{C}\right)$ with $12 \mathrm{~h}$ day and night light cycles.

\section{Induction of DM}

DM was induced by a single intraperitoneal injection of $120 \mathrm{mg} / \mathrm{kg}$ of alloxan monohydrate (Sigma, USA). After alloxan injection, blood glucose level was measured using a blood glucose meter (Glucocheck, South Africa) once daily for $48 \mathrm{~h}$ and weekly thereafter for the duration of the experiment. All rats developed hyperglycemia (blood glucose of $\geq 200 \mathrm{mg} / \mathrm{dL}$ ) and were considered diabetic. On day 28 of the experiment, all rats were humanely euthanized by isoflurane overdose in a glass chamber. Immediately after euthanasia, full-thickness skin samples were harvested from the dorsal thoracolumbar area using skin punch biopsy. Skin specimens were placed in $10 \%$ buffered formalin.

\section{Immunohistochemistry}

Skin tissue specimens were processed using a tissue processor (Leica Biosystems, USA). Briefly, tissue sections were deparaffinized in an oven at $65^{\circ} \mathrm{C}$ for $1 \mathrm{~h}$. The sections were then passed into solutions, from xylene to distilled water. To minimize or inhibit endogenous peroxidase activity, the sections were treated with $1 \%$ hydrogen peroxide in absolute methanol for $20 \mathrm{~min}$. To minimize or prevent nonspecific binding, the tissue sections were washed with phosphate-buffered saline (PBS, $\mathrm{pH}$ 7.2-7.4) for 5 min and incubated with $1 \%$ bovine serum albumin for $30 \mathrm{~min}$. During that time, the primary antibody and other immunohistochemistry reagents were prepared and brought to room temperature $\left(23-24^{\circ} \mathrm{C}\right)$. Monoclonal antibodies against HSP 90, iNOS, and VEGF were prepared (1:100) and incubated with the tissue sections for $1 \mathrm{~h}$ in a humid chamber. Thereafter, the tissue sections were washed with PBS for 5 min and incubated with secondary biotinylated antibodies for $20 \mathrm{~min}$. The sections were then washed again with PBS for $5 \mathrm{~min}$ and incubated with streptavidin-conjugated with horseradish peroxidase enzyme for $20 \mathrm{~min}$. Thereafter, the sections were washed again with PBS for 5 min. Finally, immunohistochemical reaction was assessed by incubation with diaminobenzidine until the development of a brown reaction followed by washing of the sections with tap water to stop the reaction. The sections were counterstained with hematoxylin for $30 \mathrm{~s}$, washed with water, dehydrated, and mounted with a medium. The size of the tissue specimens for immunohistochemistry staining was $1 \times 1 \times 1 \mathrm{~mm}$.

\section{Statistical analysis}

Data on HSP 90, iNOS, and VEGF were compared between groups using independent Student's t-test. Levene's test was used to assess the equality of variances. The expressions of HSP 90, iNOS, and VEGF were assessed by Adobe Photoshop Software version 7.2 (Adobe Systems Inc., California, USA). Photomicrographs of the tissue sections were captured and divided into pixels, which appeared in blue and brown; the brown color represented the marker. The number of brown pixels was computed and expressed as a ratio to the total number of blue and brown pixels. Descriptive statistics for HSP 90, iNOS, and VEGF for each group were presented as mean $\pm \mathrm{SD}$. Correlation analysis between the mean blood glucose level on day 28 and the expression levels of HSP 90, iNOS, and VEGF in diabetic rats was performed using Pearson's correlation. Statistical significance was accepted at $p<0.05$. All statistical analyses were performed using SPSS software version 19.0 (IBM Statistical Package, USA).

\section{Results}

All rats in Group 2 developed DM and maintained an average blood glucose level of $\geq 200 \mathrm{mg} / \mathrm{dL}$ throughout the study period. Table-1 presents the values of HSP 90, iNOS, and VEGF expressions in the skin of rats with alloxan-induced DM. A positive correlation $(r=0.65, p=0.01)$ was detected between the mean blood glucose level on day 28 and the expression 
levels of HSP 90, iNOS, and VEGF in diabetic rats. There was a significant difference in the skin expressions of HSP 90, iNOS, and VEGF between Groups 1 and 2 (Figures-1-3).

Table-1: Expression of HSP 90, iNOS, and VEGF in skin of alloxan-induced diabetic rats (values are expressed in mean \pm SD based on descriptive analysis using pixel count on Photoshop of immunohistochemistry images).

\begin{tabular}{lccc}
\hline Parameter & Control & Diabetic rats & p-value* \\
\hline HSP 90 & $0.09 \pm 0.02$ & $0.16 \pm 0.05$ & 0.01 \\
iNOS & $0.04 \pm 0.01$ & $0.48 \pm 0.18$ & 0.02 \\
VEGF & $0.25 \pm 0.21$ & $0.51 \pm 0.02$ & 0.05 \\
\hline
\end{tabular}

*Using independent Student's t-test. HSP 90=Heat shock protein 90, iNOS=Inducible nitric oxide synthase, VEGF $=$ Vascular endothelial growth factor, $S D=$ Standard deviation
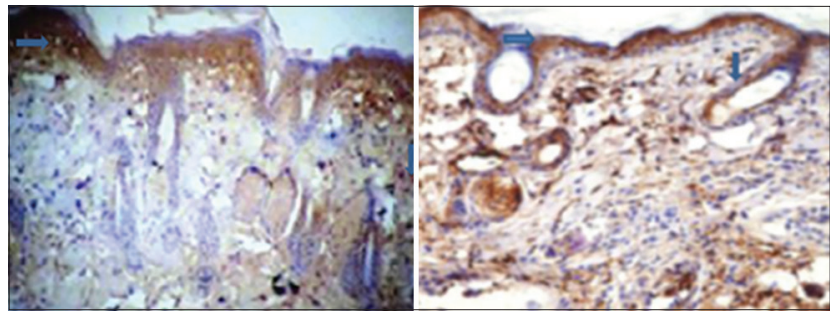

Figure-1: Immunohistochemistry image showing the extent HSP 90 expression in skin of diabetic rats (left) and control rats (right). Arrows point at brown color indicating HSP $90(40 \times)$. There was a significant difference in the expression of HSP 90 in the skin of control rats when compared to that in alloxan-induced diabetic rats. HSP $90=$ Heat shock protein 90.

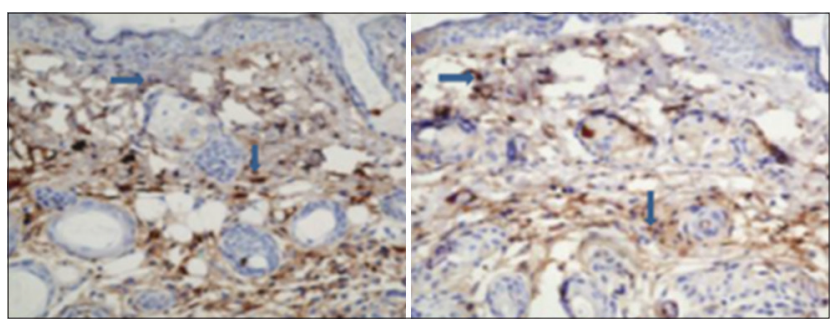

Figure-2: Immunohistochemistry image showing the extent of iNOS expression in skin of diabetic rats (left) and control rats (right). Arrow points at brown color indicate iNOS $(40 \times)$. There was a significant difference in the expression of iNOS in the skin of control rats when compared to that in alloxan-induced diabetic rats. iNOS=Inducible nitric oxide synthase.

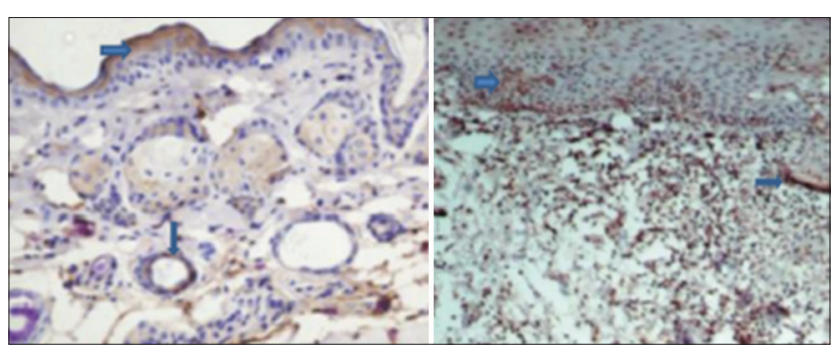

Figure-3: Immunohistochemistry image showing the extent of VEGF expression in skin of diabetic rats (left) and control rats (right). Arrows point at brown color indicating of VEGF $(40 \times)$. There was a significant difference in the expression of VEGF in the skin of control rats when compared that in alloxan-induced diabetic rats. VEGF=Vascular endothelial growth factor.

\section{Discussion}

This study was carried out to evaluate the expressions of biomarkers HSP 90, iNOS, and VEGF in the skin of normal rats and rats with alloxan-induced diabetes. The results indicated that the skin obtained from diabetic rats had significantly higher expressions of HSP 90, iNOS, and VEGF biomarkers, compared with those in the control group. Overexpression of the biomarkers HSP 90, iNOS, and VEGF in the skin of diabetic rats suggested that the cellular protective response of body is initiated by providing more factors that are required for cutaneous tissue healing and remodeling.

In this study, the dorsal thoracolumbar skin area was selected because it provides easy access and has a larger area for sample collection, compared with the foot in rats [17]. Recently, rapid accumulation of HSP $90 \alpha$ in response to tissue injury in different body cells has been suggested [18]. Moreover, secretion of HSP $90 \alpha$ by keratinocytes at the wound edge to enhance reepithelialization and, eventually, wound closure was reported $[19,20]$. In fact, wound healing has been observed to accelerate following topical application of recombinant HSP 90 $\alpha$ [19-21].

iNOS is known to be expressed in almost all cell types, including the skin [22]. iNOS was suggested to be required for wound healing, and lack of iNOS was reported to retard macrophage invasion and impaired wound healing [23]. Moreover, topical application of recombinant matricellular protein angiopoietin-like 4 was shown to accelerate wound healing by promoting reepithelialization and upregulating iNOS in the epithelium of diabetic mice $[24,25]$. Furthermore, a pro-angiogenic response through upregulation of VEGF was suggested to promote the wound healing process in diabetic rats [26].

\section{Conclusion}

The results of this study indicated that DM upregulated the expressions of HSP 90, iNOS, and VEGF in the skin tissues of diabetic rats and may impact wound healing. Although the immunohistochemistry data provided in this study may have been insufficient for a complete understanding of the complex relationships between the different parameters and DM, the results may be considered preliminary and may shed some light on the advancement of our understanding of the roles of these proteins in wound healing in patients with DM. Further studies are warranted to investigate the exact mechanisms of these relationships.

\section{Authors' Contributions}

KZA, LAR, and AJA: Designed the study, performed the laboratory analysis, and collected data. MAA: Performed the statistical analysis and reviewed the manuscript. All authors read and approved the final manuscript.

\section{Acknowledgments}

This research was funded by the Deanship of Research of Jordan University of Science and Technology (Grant number: 361-2014). 


\section{Competing Interests} interests.

The authors declare that they have no competing

\section{Publisher's Note}

Veterinary World remains neutral with regard to jurisdictional claims in published institutional affiliation.

\section{References}

1. El-Menyar, A., Mekkodathil, A. and Al-Thani, H. (2016) Traumatic injuries in patients with diabetes mellitus. $J$. Emerg. Trauma Shock, 9(2): 64-72.

2. Younis, B.B., Shahid, A., Arshad, R., Khurshid, S., Ahmad, M. and Yousaf, H. (2018) Frequency of foot ulcers in people with Type 2 diabetes, presenting to specialist diabetes clinic at a tertiary care hospital, Lahore, Pakistan. BMC Endocr. Disord., 18(1): 53.

3. Danaei, G., Finucane, M.M., Lu, Y., Singh, G.M., Cowan, M.J., Paciorek, C.J., Lin, J.K., Farzadfar, F., Khang, Y.H., Stevens, G.A., Rao, M., Ali, M.K., Riley, L.M., Robinson, C.A. and Ezzati, M. (2011) National, regional, and global trends in fasting plasma glucose and diabetes prevalence since 1980: Systematic analysis of health examination surveys and epidemiological studies with 370 country-years and 2.7 million participants. Lancet, 378(9785): 31-40.

4. Chawla, A., Chawla, R. and Jaggi, S. (20160 Microvascular and macrovascular complications in diabetes mellitus: Distinct or continuum? Indian J. Endocr. Metab., 20(4): 546-551.

5. Zhang, P., Lu, J., Jing, Y., Tang, S., Zhu, D. and Bi, Y. (2017) Global epidemiology of diabetic foot ulceration: A systematic review and meta-analysis. Ann. Med., 49(2): 106-116.

6. Muhammad, A., Arulselvan, P., Cheah, S., Abas, F. and Fakurazi, S. (2016) Evaluation of wound healing properties of bioactive aqueous fraction from Moringa oleifera Lam on experimentally induced diabetic animal model. Drug Des. Dev. Ther., 10: 1715-1730.

7. Okonkwo, U.A. and DiPietro, L.A. (2017) Diabetes and wound angiogenesis. Int. J. Mol. Sci., 18(7): 1419.

8. Zubair, M. and Ahmad, J. (2015) Plasma heat shock proteins (HSPs) 70 and 47 levels in diabetic foot and its possible correlation with clinical variables in a North Indian tertiary care hospital. Diabetes Metab. Syndr., 9(4): 237-243.

9. Bellini, S., Barutta, F., Mastrocola, R., Imperatore, L., Bruno, G. and Gruden, G. (2017) Heat shock proteins in vascular diabetic complications: Review and future perspective. Int. J. Mol. Sci., 18(12): 2709.

10. Soskić, S.S., Dobutović, B.D., Sudar, E.M., Obradović, M.M., Nikolić, D.M., Djordjevic, J.D., Radak, D.J., Mikhailidis, D.P. and Isenović, E.R. (2011) Regulation of inducible nitric oxide synthase (iNOS) and its potential role in insulin resistance, diabetes and heart failure. Open Cardiovasc. Med. J., 5: 153-163.

11. Ignarro, L.J. (2019) Nitric oxide is not just blowing in the wind. Br. J. Pharmacol., 176(2): 131-134.

12. Toda, N., Kishioka, S., Hatano, Y. and Toda, H. (2009) Modulation of opioid actions by nitric oxide signaling. Anesthesiol, 110(1): 166-181.

13. Soskić, S., Dobutović, D., Sudar, M., Obradović, M., Nikolić, M., Djordjevic, D., Radak, D.J., Mikhailidis, D.P. and Isenović, E.R. (2011) Regulation of inducible nitric oxide synthase (iNOS) and its potential role in insulin resistance, diabetes and heart failure. Open Cardiovasc. Med. J.,
5: $153-163$

14. Al-Jarrah, M., Matalka, I., Aseri, H.A., Mohtaseb, A., Smirnova, I.V., Novikova, L., Stehno-Bitte, L. and Alkhateeb, A. (2010) Exercise training prevents endometrial hyperplasia and biomarkers for endometrial cancer in rat model of type 1 diabetes. J. Clin. Med. Res., 2(5): 207-214.

15. Jude, E.B., Boulton, A.J., Ferguson, M.W. and Appleton, I. (1999) The role of nitric oxide synthase isoforms and arginase in the pathogenesis of diabetic foot ulcers: Possible modulatory effects by transforming growth factor beta 1 . Diabetologia, 42(6): 748-757.

16. Johnson, K.E. and Wilgus, T.A. (2014) Vascular endothelial growth factor and angiogenesis in the regulation of cutaneous wound repair. Adv. Wound Care, 3(10): 647-661.

17. Milan, P.B., Lotfibakhshaiesh, N., Joghataie, M.T., Ai, J., Pazouki, A., Kaplan, D.L., Kargozar, S., Amini, N., Hamblin, M.R., Mozafari, M. and Samadikuchaksaraei, A. (2016) Accelerated wound healing in a diabetic rat model using decellularized dermal matrix and human umbilical cord perivascular cells. Acta Biomater., 45: 234-246.

18. Bhatia, A., O'Brien, K., Chen, M., Woodley, D.T. and Li, W. (2016) Keratinocyte-secreted heat shock protein-90 alpha: Leading wound reepithelialization and closure. Adv. Wound Care, 5(4): 176-184.

19. Cheng, C.F., Fan, J., Fedesco, M., Guan, S., Li, Y., Bandyopadhyay, B., Bright, A.M., Yerushalmi, D., Liang, M., Chen, M., Han, Y.P., Woodley, D.T. and Li, W. (2008) Transforming growth factor alpha (TGFalpha)stimulated secretion of HSP 90alpha: Using the receptor LRP-1/CD91 to promote human skin cell migration against a TGFbeta-rich environment during wound healing. Mol. Cell Biol., 28(10): 3344-3358.

20. Woodley, T., Fan, J., Cheng, C.F., Li, Y., Chen, M., Bu, G. and $\mathrm{Li}, \mathrm{W}$. (2009) Participation of the lipoprotein receptor LRP1 in hypoxia-HSP 90alpha autocrine signaling to promote keratinocyte migration. J. Cell. Sci., 122(Pt 10): 1495-1498.

21. Cheng, C.F., Sahu, D., Tsen, F., Zhao, Z., Fan, J., Kim, R., Wang, X., O'Brien, K., Li, Y., Kuang, Y., Chen, M., Woodley, D.T. and Li, W. (2011) A fragment of secreted HSP $90 \alpha$ carries properties that enable it to accelerate effectively both acute and diabetic wound healing in mice. J. Clin. Invest., 121(11): 4348-4361.

22. Iwakiri, Y. (2015) Nitric oxide in liver fibrosis: The role of inducible nitric oxide synthase. Clin. Mol. Hepatol., 21(4): 319-325.

23. Kitano, T., Yamada, H., Kida, M., Okada, Y., Saika, S. and Yoshida, M. (2017) Impaired healing of a cutaneous wound in an inducible nitric oxide synthase-knockout mouse. Dermatol. Res. Pract., 2017: 2184040.

24. Chong, H.C., Chan, J.S.K., Goh, C.Q., Gounko, N.V., Luo, B., Wang, X., Foo, S., Wong, M.T., Choong, C., Kersten, S. and Tan, N.S. (2014) Angiopoietin-like 4 stimulates STAT3-mediated iNOS expression and enhances angiogenesis to accelerate wound healing in diabetic mice. Mol. Ther., 22(9): 1593-1604.

25. Wang, G., Lou, T., Tong, J., Zhang, L., Zhang, J., Feng, Z., Li, S., Xu, H.Z. and Mao, C. (2017) Asperosaponin VI promotes angiogenesis and accelerates wound healing in rats via upregulating HIF-1 $\alpha /$ VEGF signaling. Acta Pharmacol. Sin., 39(3): 393-404.

26. Zeng, Z., Huang, W.D., Gao, Q., Su, M.L., Yang, Y.F., Liu, Z.C. and Zhu, B.H. (2015) Arnebin-1 promotes angiogenesis by inducing eNOS, VEGF and HIF- $1 \alpha$ expression through the PI3K-dependent pathway. Int. J. Mol. Med., 36(3): 685-697. 